The Geneva Papers on Risk and Insurance, 20 (No. 75, April 1995) 197-229

\title{
Captive Insurance Tax Policy: Resolving a Global Problem
}

\author{
M. Moshe Porat* \\ Michael R. Powers**
}

\begin{abstract}
Over the past three decades, the global captive insurance movement has established itself as a significant alternative to traditional insurance. During this period, the controversy surrounding the tax-deductibility of both premiums paid to captives and reserves held by captives has never abated. In the United States, the controversy derives from a fundamental conflict within a federal tax policy that attempts to respect the legal separateness of corporate entities, while at the same time questioning the economic substance of transactions between affiliated entities. Because many nations' tax authorities follow the lead of the U.S. Internal Revenue Service on this issue, a resolution of the controversy is of global interest.
\end{abstract}

In this article, the fundamental principles underlying the tax-deductibility of both insurance premiums (for the insured) and insurance reserves (for the insurer), are examined from both theoretical and practical perspectives. The authors then propose a heuristic method for justifying the tax-deductibility of premiums based upon an index that measures: (1) the extent to which the captive is constrained by market forces to engage in the "business of insurance," and (2) the efficiency of risk transfers. The deductibility of reserves is addressed by a special case of the index.

This approach provides a unified resolution to issues of tax policy for captive insurers that allows for partial solutions in the spectrum from no tax-deductibility to full tax-deduc-

\footnotetext{
*Joseph E. Boettner Professor of Risk Management and Insurance and Chairman of the Department of Risk Management, Insurance, and Actuarial Science, Temple University's School of Business and Management.

** Assistant Professor of Risk Management and Insurance, Temple University.

The authors wish to thank Imelda Yeung Powers and G. Ruben Tsui for their assistance in producing various figures and exhibits.
} 
tibility, and provides consistent solutions to all arrangements involving captives, including variations in the ownership structure and in the types of business written. The authors argue that the approach is both theoretically sound and intuitively appealing; that it is consistent with the U.S. government's established policy of favoring traditional insurers over alternative risk management techniques; and that it is fair and reasonable to all parties, reducing incentives for abuse, litigation, and distortions of economic activity.

\section{Introduction}

Over the past three decades, the global captive insurance movement has won the respect and favor of many risk managers and insurance practitioners, presenting a formidable challenge to traditional insurance. Today, it is estimated that there are approximately 3,400 captive insurers worldwide, accounting for about 6 to 6.5 percent of U.S. commercial property-liability insurance premiums ${ }^{1}$. As the popularity of captive insurers has increased, controversy surrounding the tax-deductibility of both premiums paid to captives and reserves established by captives has continued unabated.

In the United States, the federal government, through law and the regulations of the Internal Revenue Service (the "Service"), has never faltered in its determination to disallow tax deductions for risk financing mechanisms other than the purchase of insurance from a traditional insurer. While the federal courts have generally supported this basic policy, they have often disagreed with the government's rationales.

The captive insurance tax controversy derives from a fundamental conflict within a federal tax policy that attempts to respect the legal separateness of corporate entities, while at the same time questioning the economic substance of transactions between affiliated entities. Had the issue been limited to wholly owned captives covering only the risks of their parent owners, the controversy would undoubtedly have subsided long ago. However, over time, various derivatives of the captive movement-group ownership, the writing of unrelated risks, and the writing of risks from brother/sister subsidiaries-have created new situations to challenge existing tax policy and case law. Because many nations' tax authorities follow the lead of the U.S. Internal Revenue Service on this issue, a resolution of the controversy is of global interest.

In Section 2 of this article, the history of the captive insurance movement is summarized, and the motives and purposes for captive formation are discussed. In Section 3, we describe the basic differences between captive insurance and traditional insurance, and introduce two fundamental efficiency measures that provide clear insight into these differences. In Section 4, our assumptions regarding the tax treatment of traditional insurers, self-insurers, and captives are presented, and then, in Section 5, we propose a set of standards for evaluating the tax treatment of captive insurers. In Section 6 , the practical steps necessary to implement these standards, including the calculation of a heuristic tax-deductibility index, are described; the application of the approach is illustrated through a number of instructive examples in Section 7. Finally, we summarize our approach in Section 8.

\footnotetext{
I See, for example, 1994 Captive Insurance Companies Directory, Tillinghast: Stamford, CT.
} 


\section{The Captive insurance movement}

\subsection{Historical perspective}

Captive insurance is not a new technique for handling the risk exposures of a business enterprise. The origins of the captive insurance movement can be traced to the early $1920 \mathrm{~s}$ and even earlier, both in the United States and other nations. A number of the first mutual insurance companies began as captives; for example, the first "factory mutual" company was established as a captive by a group of manufacturers who owned well-constructed, highly protected properties. In the late 1920s, the Church Insurance Company was formed by the Episcopal Church. In 1919, the F. L. Smidth Company of Denmark formed Forenede Assurandorer A/S, which is currently one of the largest non-U.S.-owned captive insurers.

Although the captive insurance concept is not a new one, captives were not widely used in corporate risk management until about three decades ago. The modern history of captives as a tool in risk management began in the mid to late 1960 s when energy and chemical companies experienced difficulties in acquiring insurance from the traditional commercial property-liability market, and continued with the medical malpractice, product liability, and general liability crises of the early 1970 s, when these types of coverages became unavailable and/or unaffordable in the conventional commercial insurance markets.

\subsection{Motives for captive formation}

The formation of new captive insurers has been driven in large part by capacity shortages in the traditional insurance markets. However, the accelerated growth of captives can also be attributed to the desires of corporations to realize cost savings, to achieve coverage flexibility, and generally to gain greater control over their own fortunes.

Among the potential cost savings of captives, tax benefits that could be achieved through premium and/or reserve tax-deductibility were prominent incentives from the very beginning. While other presumed tax advantages associated with foreign captives (e.g., foreign tax credits, deferrals in repatriating profits or investment income, etc.) largely disappeared through changes in tax law and regulation, the potential for premium and/or reserve deductibility was further encouraged through the promotion of organizational and operational structures presumed to enhance such tax advantages. Ultimately, however, most captive operators have realized that the primary financial motivations for forming captives are the potential for lower loss costs, lower expenses, lower reinsurance costs, improved cash flows, and increased investment yields.

Often overshadowed by these cost savings were operational advantages provided by captives in the form of capacity, coverage flexibility, access to reinsurance markets, stabilization of financial statements, and control over one's own insurance programs, as well as other services of particular importance to multinational companies, such as overcorning currency control problems and consolidating insurance programs. During the captive movement's dramatic growth of the late $1970 \mathrm{~s}$, a new motive was added: corporate officers were encouraged to form captives simply because their competitors were doing so-i.e., captive formation also became a way of keeping up with the prestige of one's peers. 


\subsection{Types of captives}

Some of the earliest captive insurers were formed as wholly owned subsidiaries of a parent owner. However, many of the early captives that were formed in response to problems faced by entire industries (such as the energy, chemical, medical, and manufacturing sectcrs) were group-owned, having been established either by trade associations or groups of individuals and corporations.

Most captive insurers, whether wholly owned or group-owned, were initially formed as pure captives-that is, captives writing only the risks of their parents. However, once it became clear that tax deductions would largely be disallowed for premiums and reserves associated with wholly owned pure captives, the movement spawned various types of broad captives - that is, captives writing some unrelated (third party) risks in addition to those of their parents. These broad captives were formed under the assumption that taxdeductibility would be permitted if, in addition to the parent's risks, the captive covered some number of unrelated risks or the risks of related subsidiaries of the parent that did not own the captive.

Unfortunately for many broad captives, the soft property-liability insurance market of the early 1980s turned out to be costly, and in some cases devastating. Many captives writing unrelated risks for the presumed tax benefits were not sufficiently prudent in underwriting and managing these exposures to be profitable; some of these captives actually became insolvent or ceased operations voluntarily.

Despite the ups and downs in the fortunes of individual captive insurers, the captive insurance movement as a whole has survived its maturation process, largely shed itself of exploratory ventures, and refocused attention on the primary purpose of achieving the goals of the parent corporation. Today's captive insurers come in a wide variety of forms, both in terms of ownership and operations. Some captives are simply formalized self-insurance programs, whereas others function as full-fledged insurers; a few are little more than a folder at a lawyer's office, whereas others possess all of the characteristics commonly associated with a traditional insurance company.

\subsection{A definition}

Although captive insurers may be formed for any combination of financial, operational, or social/psychological reasons-and these reasons may change over time-the basic description of a captive today remains the same as it always has been:

- a formal entity owned by another corporation, individual, or group of corporations and individuals; and

- an entity established primarily to cover the risks of the corporations and/or individuals that own it.

Thus, a good operational definition of a captive insurer is: a formal insurance subsidiary established primarily to finance the risks of its owners. 


\subsection{The future of captive insurance}

The global captive movement has become an important part of the alternative property-liability insurance market. Current estimates suggest that the alternative market, including captive insurers, risk retention groups, pools, and self-insurers has grown to about one-third the size of the traditional commercial insurance market in the United States, and captives are estimated to comprise approximately 20 to 25 percent of the alternative market ( $\$ 12$ to $\$ 15$ billion out of the approximately $\$ 60$ billion alternative market). As of 1993, it was estimated that there were approximately 3,300 captive insurers worldwide, and that captives accounted for about 6 percent of U.S. commercial property-liability insurance premiums ${ }^{2}$.

The captive movement and the alternative market are here to stay, regardless of their tax treatment. This is because these alternative risk financing mechanisms have been developed as a response to the key problems of the traditional insurance market: capacity shortages, coverage inflexibility, vacillating costs, and lack of sufficient input and control by the insured. All alternative mechanisms employing some form of risk retention have provided some relief in these areas. Captive insurers, however, provide more flexibility and control than the other methods because they permit the possibility of changing goals and operations in ways that are impossible for risk retention groups, pools, and self-insurers. We believe that captives, in both their wholly owned and group-owned forms, will continue to grow in popularity among both U.S. and international insureds. While the growth in offshore captive insurers will come primarily from international insureds, the growth in domestic captives will come from medium- and large-size insureds as well as from associations and groups of insureds.

\section{Captives vs. traditional insurers}

\subsection{Two efficiency measures}

Any entity in the business of insurance is essentially involved in the bearing and management of risk. In the traditional insurance market, an insurer is an organization (company or association) subject to various competitive market forces that impose upon the insurance entity certain activities, transactions, and compliances common to the business of insurance. These market forces further ensure that the entity will carry out its operations in an economically efficient manner; otherwise, it will not survive in the long run.

When an insurance entity seeks to write primarily or exclusively the risks associated with the interests that own the entity, as in the case of a captive insurer, the market forces prevailing in the traditional market are inhibited. A captive may appear to possess all of the characteristics of a traditional insurer, but, because it is owned by one of its customers, it is not constrained by market forces to maintain the same level of operational independence as the traditional insurer; this reduction in operational independence creates the potential for a decrease in operational efficiency. Both the extent of ownership by the parent and the proportion of unrelated business affect the degree of operational independence, so that a wholly owned pure captive would be completely removed from the effect

2 See, for example, Conning and Company Report, 1993. 
of market forces, but a wholly owned broad captive with substantial outside business or a group-owned captive in which the parent has a small ownership share would be subject to market forces almost to the same degree as a traditional insurer.

In addition to the reduction in operational efficiency, the transfer of risk from a parent to a captive insurer is intrinsically less efficient than a similar transfer to a traditional insurer because all or part of the parent's insured losses ultimately remain the responsibility of the parent through its ownership of the captive. It is simply the extent of ownership of the captive by its parent that directly affects the transfer efficiency of the insurance transaction. A risk transfer to a wholly owned captive will be completely inefficient in the sense that all of the parent's insured losses ultimately remain the parent's own financial responsibility, whereas a risk transfer to a group-owned captive in which the given parent has a very small ownership share would be almost as efficient as an insurance transaction with a traditional insurer.

In Section 5, the concepts of operational independence and transfer efficiency will be defined as measurable quantities. These two quantities are somewhat positively related because they both tend to increase as the parent's ownership of the captive decreases. (This behavior is shown schematically in Figures 1 and 2.) In the extreme case of a traditional insurer, both quantities would reach their highest possible levels, whereas in the case of a self-insurer or wholly owned pure captive, both quantities would vanish.

\section{Fig. I Operational Independence vs. Captive Ownership}

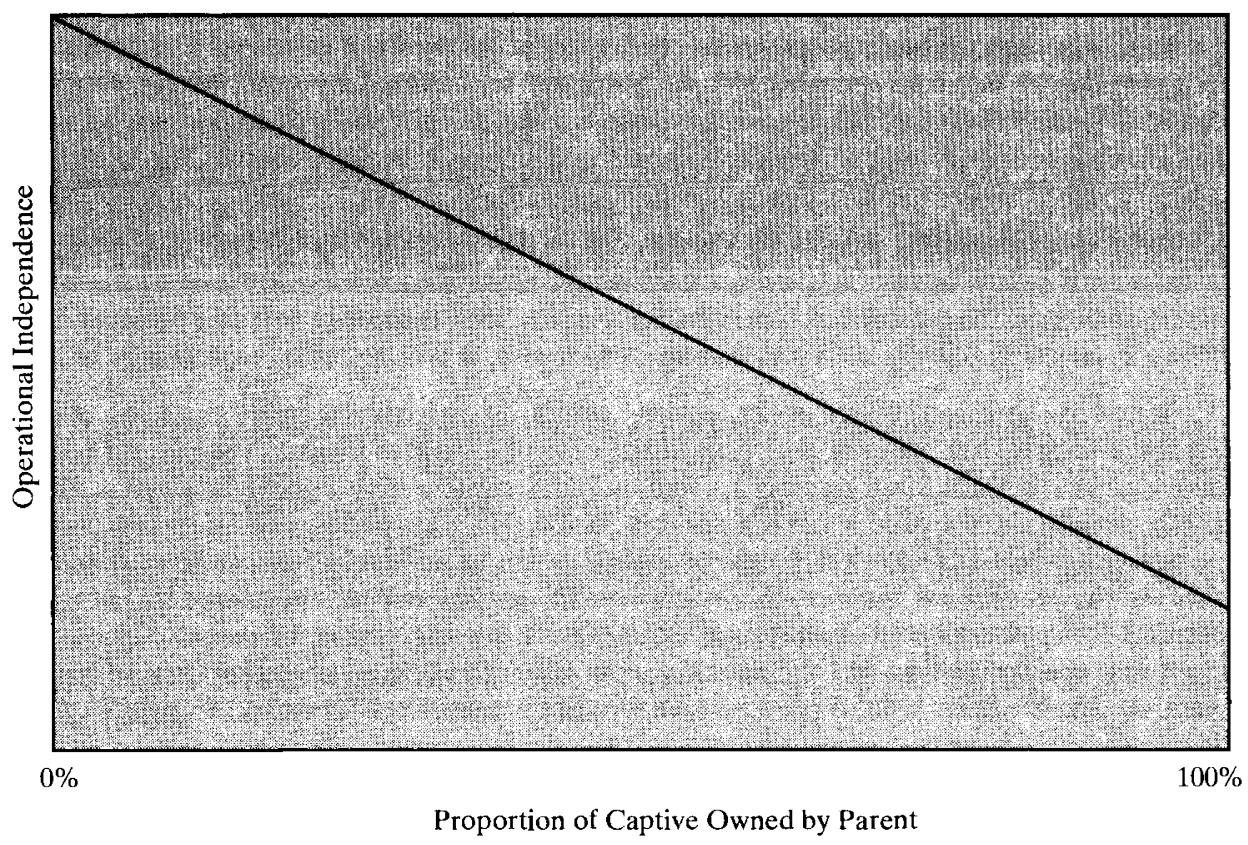




\section{Fig. 2 Transfer Efficiency vs. Captive Ownership}

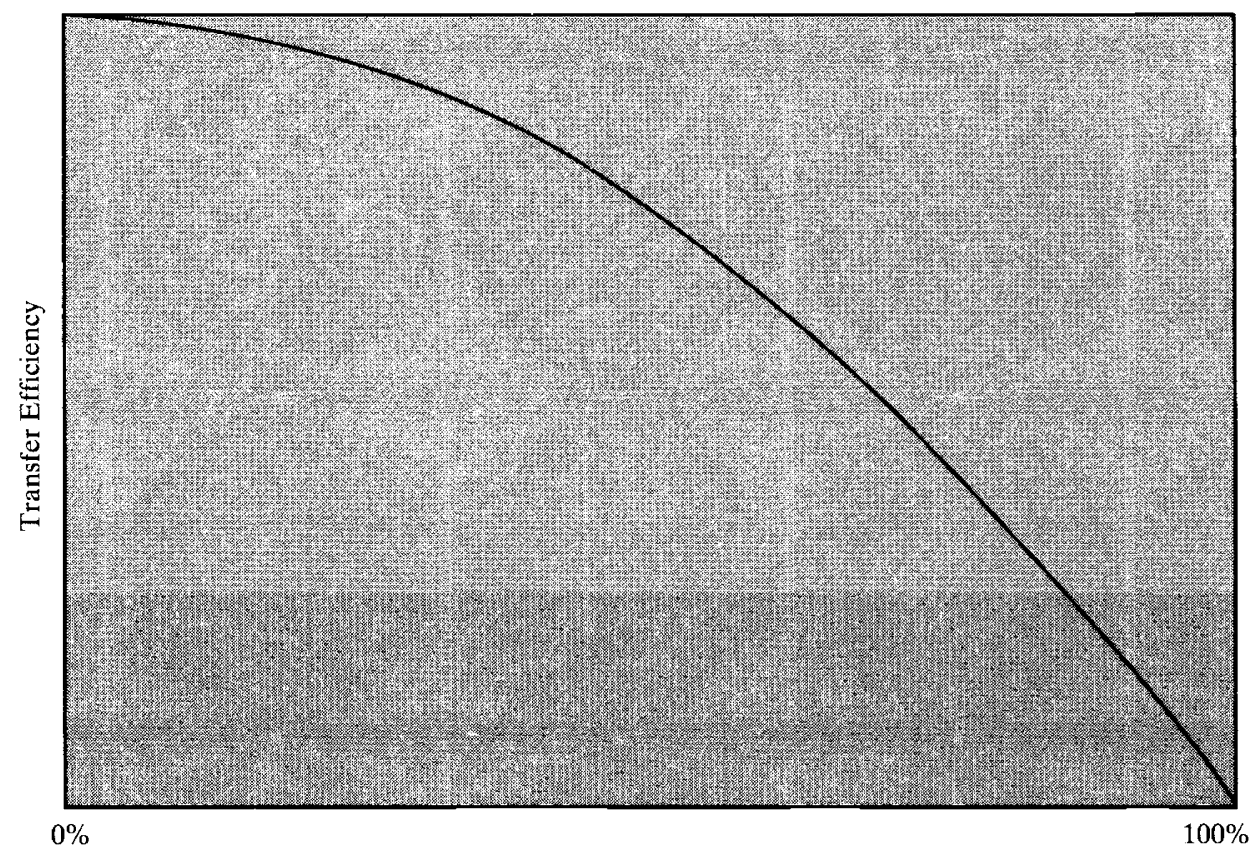

Proportion of Captive Owned by Parent

Nevertheless, it is possible to have a high level of one quantity and a low level of the other. This is because the operational independence of a captive insurer is also affected by the proportion of unrelated business in the captive's portfolio, increasing as the proportion of unrelated business increases (see Figure 3 for a schematic diagram of this behavior). For example, consider the case of a wholly owned broad captive that writes a large amount of unrelated business. As indicated above, this type of captive would be subject to market forces almost to the same degree as a traditional insurer, ensuring high operational independence. At the same time, any insured losses of the parent would ultimately remain the full responsibility of the parent, resulting in no transfer efficiency. Note that if the unrelated business of this type of broad captive consisted primarily of risks associated with other subsidiaries of the parent, then the operational independence of the captive would be compromised to the extent that the subsidiaries were forced or coerced to buy insurance from the captive and also to the extent that the subsidiaries are involved, directly or indirectly, in the fortunes of the captive. 


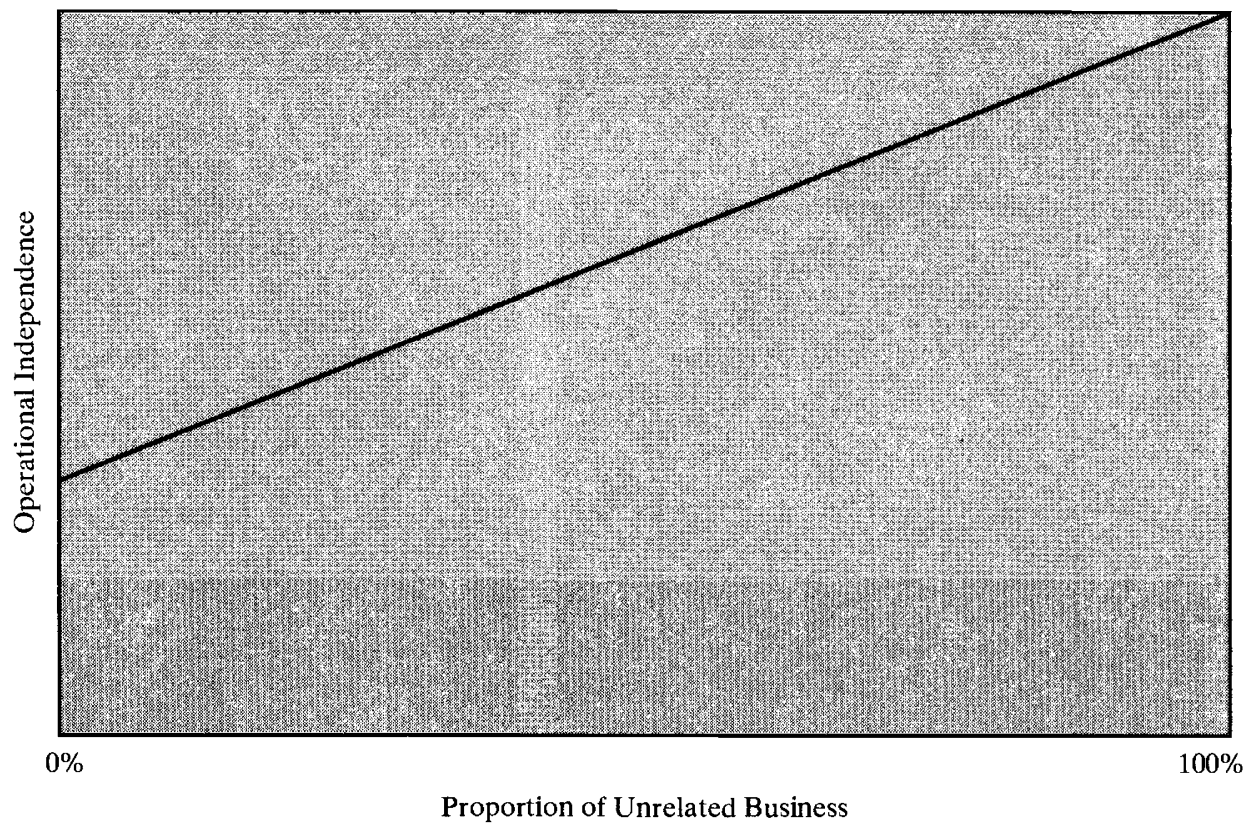

\subsection{Prominent captive cases-an efficiency analysis}

Driven by the desire to enjoy the tax benefits available to traditional insurers but denied to self-insurers, many captive insurers have attempted to engage in activities that mimic the operations and transactions of traditional insurers. They have adopted formal business purposes, fully complied with their domicile's regulation, acquired sufficient capital, developed in-house expertise, conducted transactions at arm's length; some captives have even embarked upon writing unrelated business or relinquished partial ownership by the parent.

Regardless of the degree to which a captive mimics the business operations of a traditional insurer, we believe that the two quantities described above-operational independence and transfer efficiency-form the fundamental basis for comparing the economic efficiency of an insurance transaction involving a captive to a similar transaction involving a traditional insurer. Operational independence tells us to what degree the captive is constrained by market forces to engage in the business of insurance, and transfer efficiency tells us to what degree the transfer of risk makes economic sense.

In Figure 4, we show how these two fundamental quantities may be used to analyze the insurance transactions associated with a number of captives from prominent legal cases. Starting with the lower left-hand corner, we see that the Carnation case involved a 
captive that was effectively a formal self-insurance program ${ }^{3}$. There was no operational independence because the captive was a pure captive, writing only its parent's risks, and therefore not subject to market forces. There was no transfer efficiency because the captive was wholly owned, and so the parent remained fully responsible for the insurance losses paid by the captive.

\section{Fig. 4 Analysis of Prominent Captive Cases}

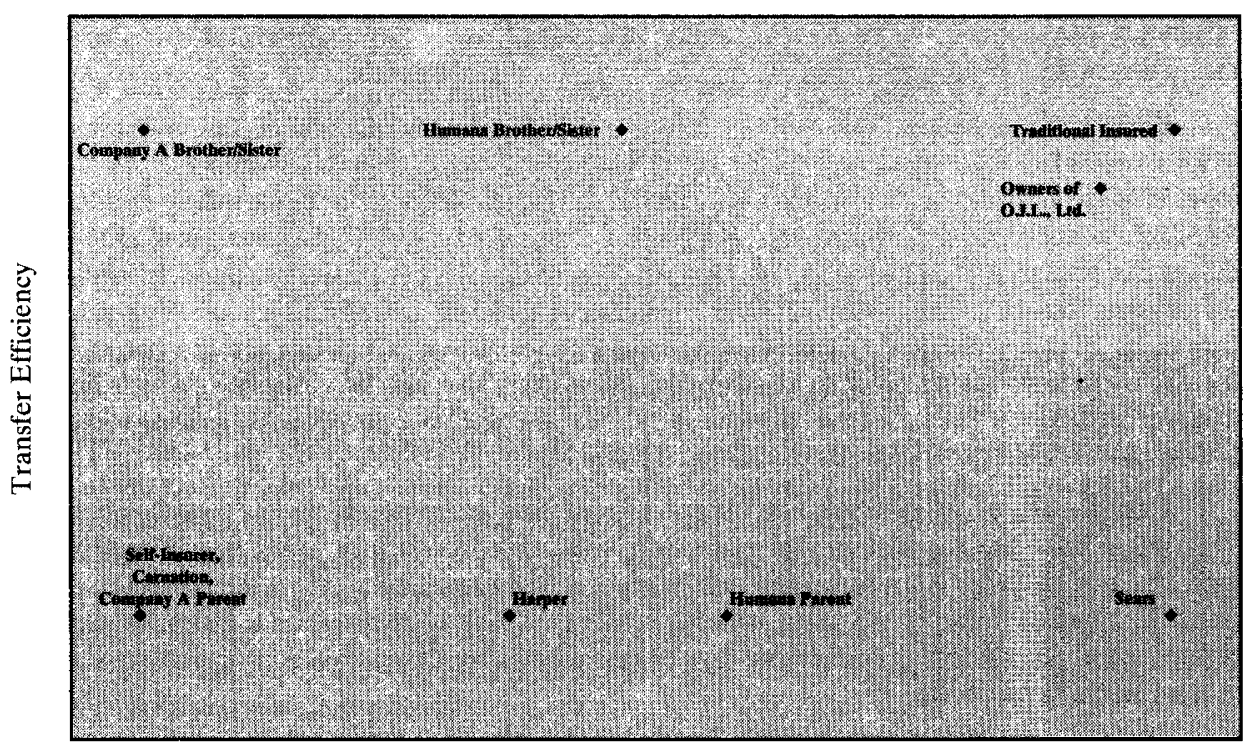

Operational Independence

Moving all the way to the upper right-hand corner of Figure 4, we see that the case of the owners of O.I.L., Limited was very similar to that of a traditional insured because the captive had many independent customers that subjected it to market forces and afforded it substantial operational independence, and because there were equally many parent entities, each of which owned only a small part of the captive, so that there was also substantial transfer efficiency ${ }^{4}$.

The celebrated cases of Harper, Sears, and the Humana parent fall along the horizontal axis of the diagram because these cases involved captives that were wholly owned, and thus devoid of transfer efficiency ${ }^{5}$. The degree of operational independence associated

${ }^{3}$ Carnation Co. v. Commissioner, 71 T.C. 400 (1978) Aff'd. 640 F.2d 1010 (9th Cir. 1981).

4 O.I.L., Ltd., Revenue Ruling 78-338, 1978-2 C.B. 107.

5 The Harper Group v. Commissioner, 96 T.C. 45 (1991) Aff'd 979 F.2d 1341 (9th Cir. 1992), Sears v. Commissioner, 96 T.C. 61 (1991) Aff'd in part and rev'd in part, 972 F.2d 858 (7th Cir. 1992), and Humana v. Commissioner, 881 F.2d 247 (6th Cir. 1989) Aff'g in part and rev'g in part, 88 T.C. 197 (1987). 
with each case was directly related to the proportion of unrelated business in the captive's portfolio. In the case of the Humana parent, this unrelated business consisted of risks from various brother/sister subsidiaries of the parent, and the partial operational independence resulted from the fact that these subsidiaries were presumably not forced or coerced to purchase insurance from the captive.

The insurance transactions of the Humana brother/sister subsidiaries also involved partial operational independence because the parent's purchase of insurance was presumably independent of the subsidiaries' purchases. In this case, there was complete transfer efficiency because the subsidiaries, unlike the parent, were not responsible for the insurance losses paid by the captive.

Finally, we consider the case of Hypothetical Company A, which has established a wholly owned captive insurer to write exclusively the risks of $A$ and its subsidiaries. In this case, it is assumed that the brother/sister subsidiaries are forced or coerced by the parent to purchase insurance from the captive, and so there is no operational independence from either the parent's or subsidiaries' perspective; hence, both the parent and the subsidiaries fall along the diagram's vertical axis. The brother/sister subsidiaries of Hypothetical Company $A$ enjoy complete transfer efficiency because the subsidiaries are not responsible for the insurance losses paid by the captive. However, the parent company, which has no transfer efficiency because the captive is wholly owned, is conceptually equivalent to a self-insurer with regard to both efficiency measures.

The quantities of operational independence and transfer efficiency are much more instructive than the concept of risk reduction-i.e., the decrease in average risk associated with the law of large numbers-for analyzing the substance of captive insurance transactions. In Figures 5 and 6, we show schematically that risk reduction, as a measure, fails to reflect either the extent of ownership by the parent or the proportion of unrelated business in the captive's portfolio.

Fig. 5 Average Risk vs. Captive Ownership

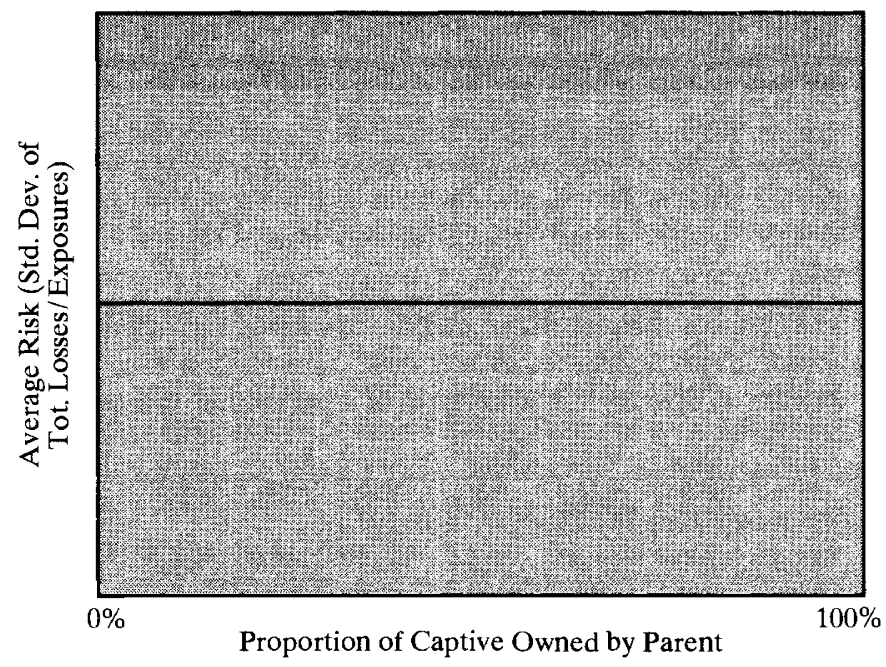


Fig. 6 Average Risk vs. Unrelated Business

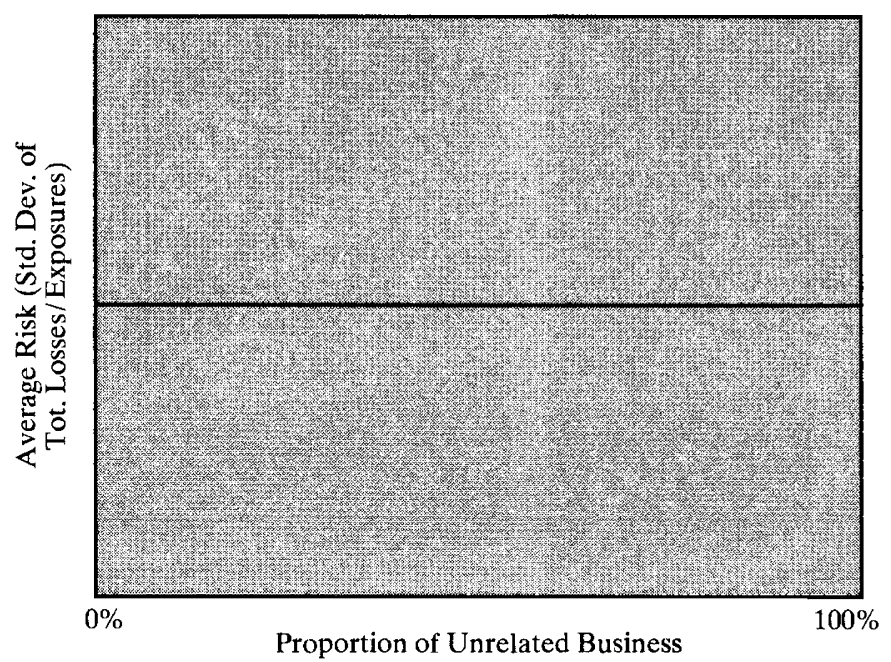

The fact that risk reduction is unaffected by the proportion of unrelated business may appear surprising since the courts considered this proportion an important criterion in permitting tax deductions in the Harper, Amerco, and Sears cases ${ }^{6}$. However, as can be seen from the schematic diagrams in Figures 7 and 8 , the average risk of a captive insurer decreases as the total number of statistically independent exposure units increases, whether these exposures are related or unrelated to the parent. Thus, it is the operational independence of the captives, rather than risk reduction, that justifies tax-deductibility in the Harper, Amerco, and Sears cases.

Fig. 7 Average Risk vs. Related Exposures

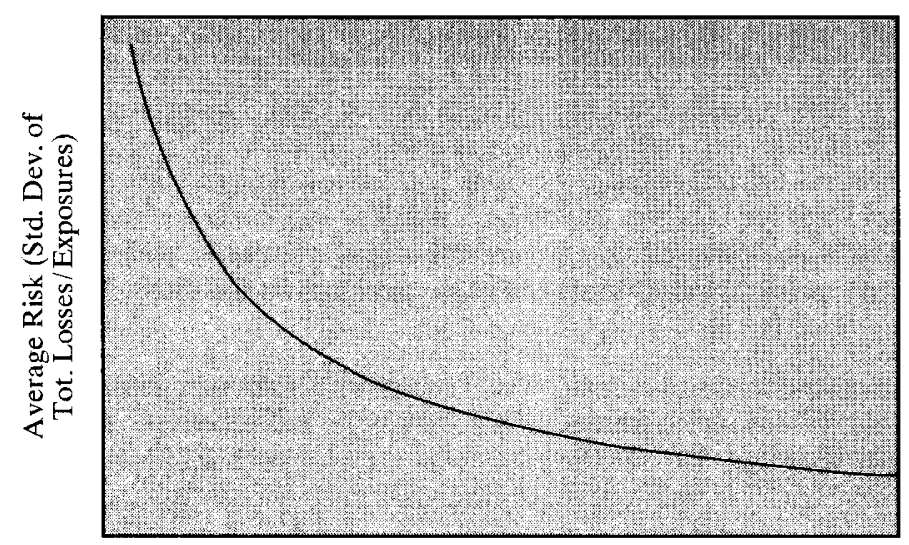

Number of Related Exposure Units

${ }^{6}$ Amerco v. Commissioner, 96 T.C. 18 (1991) Aff'd 979 F.2d 162 (9th Cir. 1992). 
Fig. 8 Average Risk vs. Unrelated Exposures

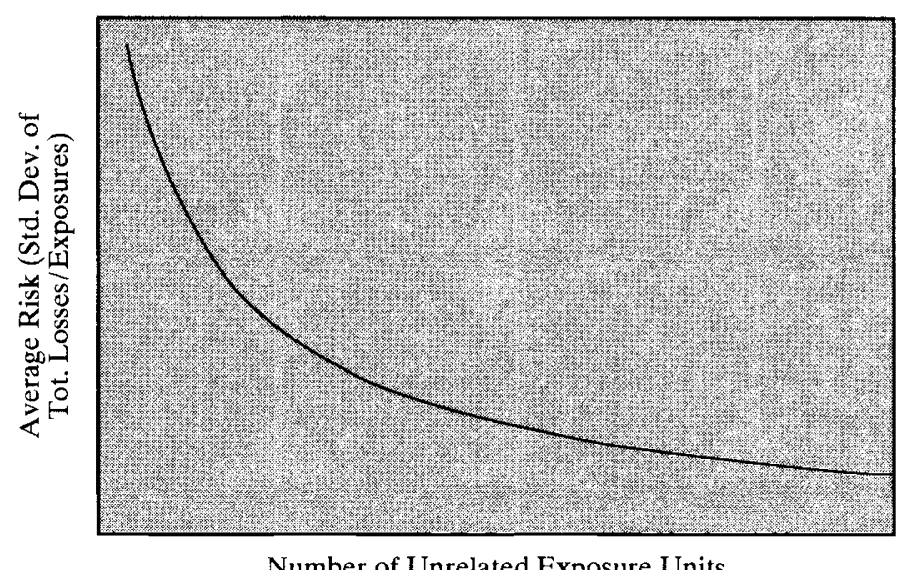

\section{Assumptions regarding the taxation of insurance}

\subsection{Traditional insurance vs. self-insurance}

In the United States, the authorization to deduct certain types of business expenses comes from the Internal Revenue Code. An expense is commonly deductible in the computation of taxable income if either: (1) the expense is specifically identified by a section of the Revenue Code, or (2) the expense is ordinary, necessary, reasonable in amount and incurred in connection with a trade or business, and the expense is not a capital expenditure, personal expenditure, or an expenditure related to tax-exempt income or contrary to public policy.

Insurance tax policy in the United States has consistently favored transfers of risk to traditional insurers over alternative risk management techniques, most notably self-insurance. This bias goes back as far as the Tariff Act of 1909, and has persisted through subsequent laws up to and including the Tax Reform Act of 1986. The principal advantage given to traditional insurance over self-insurance is that traditional insurers can deduct reserve amounts established for unearned premiums and losses incurred but not yet paid (including losses incurred but not yet reported), whereas self-insurers are afforded no such deductions ${ }^{7}$. Traditional insurers are given further preferential treatment in that only insurance premiums paid to traditional insurers are tax-deductible as general business expenses ${ }^{8}$.

Researchers attempting to justify the U.S. government's insurance tax policy have emphasized that traditional insurance: (1) enhances loss control and prevention, (2) improves claims handling, (3) satisfies the requirements of bondholders, and (4) lowers transaction costs. However, none of these observations provides any theoretical or empiri-

\footnotetext{
${ }^{7}$ Internal Revenue Code, Sections 801-46. (Supp. v. 1987)

${ }^{8}$ Internal Revenue Code, Section 162 and Treasury Regulation 1.162-1(a).
} 
cal evidence that traditional insurance is superior to alternative risk financing methods in accomplishing the most widely accepted objective of the firm-increasing its value to its equity owners ${ }^{9}$. In fact, modern financial theory reveals that from the owner's perspective, risk can be as effectively managed through self-insurance as through traditional insurance, and perhaps even more economically ${ }^{10}$.

Our best explanation for the government's unwillingness to grant self-insurers tax advantages similar to those of traditional insurers is the reasonable concern that self-insurance transactions are less likely to be economically efficient because they are not subject to the economic forces of the insurance marketplace. In other words, the government appears to have interpreted the Revenue Code's language of "ordinary, necessary, and reasonable" to imply that, for a corporate business expense to be consistent with public policy, and therefore fully tax-deductible, the associated transaction must be economically efficient from the corporation's perspective ${ }^{11}$.

Thus, loss reserves for self-insurance are not tax-deductible because they involve transactions that are not subject to the economic forces of the insurance market, and therefore potentially inefficient. Even if a self-insurer establishes reserves in an "arm'slength" manner, imitating the actuarial methodologies and capital requirements of traditional insurers, there will always remain the potential for inefficiency. For example, a selfinsurer may have economic incentives to manage the investment of reserves in a manner that is much different from (and possibly riskier than) a traditional insurer.

\subsection{The case of captives}

The Internal Revenue Code has not defined insurance, much less captive insurance. However, the Code has defined an insurance company, under Subchapter L, as any company more than one-half of whose business during the taxable year is composed of the issuing of insurance or annuity contracts or the reinsuring of risks underwritten by insurance companies ${ }^{12}$. Clearly, this definition focuses on the transaction of insurance through insurance contracts, and in a larger sense on the nature of the business of insurance as it is commonly practiced.

The primary area of controversy in captive insurance tax policy has been the question of whether premiums paid to captives, and reserves held by captives, are tax-deductible as corporate business expenses. The essence of the controversy lies in a conflict between two fundamental tax doctrines that collide in the case of captive insurers.

One established tax doctrine requires that the legal separateness among affiliated corporate entities, including a parent corporation and its captive insurer, be respected for

\footnotetext{
${ }^{9}$ See George L. Head and M. Moshe Porat, 1990, “Tax Treatment of Pre-Loss Risk Financing Cost-A Public Policy Perspective," Journal of Insurance Regulation, 8, 4, 394-407.

10 See M. Moshe Porat, et al., 1991, "Market Insurance Versus Self-Insurance: The TaxDifferential Treatment and Its Social Cost," The Journal of Risk and lnsurance, 58, 4, 657-669.

11 While the Service does not audit every business transaction to insure its economic efficiency, certain classes of transactions that can be clearly identified as inefficient or potentially inefficient are not permitted full tax-deductibility. For example, corporate entertainment expenses are only partially tax-deductible.

${ }^{12}$ Internal Revenue Code, Section 816(a).
} 
tax purposes ${ }^{13}$. Thus, a legitimate business transaction between a parent and its captive or between a brother/sister subsidiary and an affiliated captive would, at least facially, appear to be tax-deductible, like any other business expense.

However, a second long-standing tax doctrine, whose objective is to curtail tax avoidance, legitimately questions the economic substance of inter-company transactions within an affiliated group to make sure that the companies are not using legal separateness simply to minimize taxes ${ }^{14}$. For example, if the purchase of insurance by a parent from its captive were deemed to be nothing more than self-insurance under the guise of an inter-company transaction, then U.S. law would prohibit tax deductions.

To avoid conflict with the doctrine of the legal separateness of corporations while still denying the tax-deductibility of premiums paid to captives and reserves held by captives, the Service invoked its theory of the "economic family," which treated the parent and the captive as one unit for purposes of evaluating the economic impact of risk reduction ${ }^{15}$. The Service first advanced this theory in Revenue Ruling 77-316, which addressed the case of wholly owned pure captives (i.e., wholly owned captives covering only the parent's risks) ${ }^{16}$. Although the federal courts have generally been skeptical of this theory, they nevertheless accepted the Service's contention that purchasing insurance from a wholly owned subsidiary with no risks unrelated to the parent did not remove the economic consequences of risk from the parent, and therefore should not be a tax-deductible expense.

\subsection{Captive derivatives}

Had the captive insurance movement not ventured beyond wholly owned pure captives, the tax-deductibility controversy would probably have died down without significant additional litigation. This is because it is unlikely that the Service and the courts would ever have treated these captives differently from self-insurance. However, over the years, the captive movement spawned various derivatives, both in terms of ownership structure and in terms of types of business written, that have kept the controversy alive.

In the late 1970 s, most captive insurers were wholly owned, and only a few attempted to write risks unrelated to their parents. By the mid 1980s, however, more than one-third of all captives were group-owned, and about one-half had written some amount of unrelated business ${ }^{17}$. The proliferation of these derivative entities, some of which were owned by

13 The tax doctrine of recognizing the separateness of affiliated corporate entities was established by the U.S. Supreme Court in the case of Moline Properties, Inc. v. Commissioner, 319 U.S. 436 (1943) and recently reaffirmed in the case of Commissioner v. Bollinger, $108 \mathrm{~S}$. Ct. 1173 (1988).

14 This concept was affirmed by the U.S. Supreme Court in the case of Knesh v. U.S., 364 U.S. 361 (1960). The Revenue Code contains several provisions to deny the tax-deductibility of transactions with no economic substance.

15 Although it was never explicitly supported by the courts, this theory did form the basis for many cases won by the Service in the late 1970 s and the $1980 \mathrm{~s}$.

${ }_{16}$ This ruling represented the first major confrontation between the Service and the captive movement. Although criticized by many, it is still valid and has been largely affirmed by the courts (although on varying grounds).

17 See, for example, M. Moshe Porat, 1988, "Captive Insurance Companies: Concepts, Developments, and Risk Management Applications," in Issues in Insurance, Malvern, PA: American Insurance Institute. 
large parents paying large insurance premiums, elevated the issue of the tax-deductibility of premiums to greater prominence, while the issue of reserve deductibility was less frequently the subject of contention. To respond to the growing trend of writing unrelated business, the Service extended its theory of the economic family to negate completely the tax-deductibility of insurance premiums paid to a wholly owned captive, regardless of the amount of unrelated business in the captive's portfolio ${ }^{18}$.

The major problem with this strategy was no longer the possible conflict with the legal separateness of corporate entities, but rather that the Service's theory ran counter to what the courts perceived insurance to be. Consequently, the focus of the conflict shifted to the theoretical examination of the definition of insurance.

Struggling to develop a coherent approach capable of respecting arrangements that intuitively look like insurance, while still denying tax deductions in the case of wholly owned pure captives, the courts resorted to a definition of insurance advanced by the Supreme Court in the case of Helvering $v$. LeGierse, in which insurance was described as consisting of "risk shifting" and "risk distribution" 19 . In a series of important decisions, the courts rejected the Service's economic family theory, determining that the writing of unrelated risks comprising as little as 30 percent of a captive's business could make the captive a genuine insurer ${ }^{20}$. The courts' rationale was that substantial unrelated exposures cause both risk shifting and risk distribution to take place.

Another significant defeat for the government's position occurred in the case of Humana, where the Service attempted to deny the tax-deductibility of premiums paid by both a parent and a number of subsidiaries of the parent to a captive insurer owned largely by the parent ${ }^{21}$. In this case the government, relying on a version of the economic family theory commonly known as the "net worth" approach, argued that in reality risk and premium do not leave the corporate group. Thus, from the perspective of the group as a whole, the net effect of insurance purchased from a captive is tantamount to self-insurance. The Federal Appellate Court ultimately decided to allow tax deductions for premiums paid by brother/sister subsidiaries but not for premiums paid by the parent. The Court's reasoning was based upon a "balance sheet" analysis recognizing that from the perspective of the brother/sister subsidiary, risk has in fact been shifted because losses paid by the captive are not reflected in the subsidiary's financial statement ${ }^{22}$. In upholding the principle that the subsidiary is further removed from the captive than is the parent, we believe that the Court also implicitly recognized the independent responsibility and accountability of the subsidiary's management in making various decisions, including the purchase of insurance.

Another issue that has not been resolved is the general tax policy for group captives with an arbitrary number of parents and arbitrary ownership proportions. In Revenue

18 In fact, Revenue Ruling 88-72 stated that the economic family theory supporting Revenue Ruling 77-316 is not affected by the presence of unrelated risks.

${ }^{19}$ Helvering v. Le Gierse, 312 U.S. 531 (1941).

${ }^{20} O D E C O$ v. U.S., 24 Cl. Ct. 714 (1991), 92-1 U.S.T.C. 50,018 and the Sears, Amerco, and Harper cases.

21 See the Humana case.

22 This approach has been supported recently in Malone and Hyde v. Commissioner, T.C. Memo 1993-585, 66 T.C.M. 1551 (CCH). 
Ruling 78-338, the Service allowed the tax-deductibility of premiums paid to a captive owned by a group of 31 unrelated parties, where no one party's exposure exceeded five percent of the total amount insured ${ }^{23}$. This case is perceived by most observers as approximating pooling in the manner of some mutual insurers and reciprocals; thus, it does not shed light on other group-owned arrangements in which certain parents own substantial portions of the captive. Furthermore, few other cases of group captives have been litigated (because most cases either have been subject to Revenue Ruling 78-338 or have received a private ruling), and so there is little case law upon which to build tax policy.

Currently, the Service permits a parent corporation to deduct premiums paid to its captive insurer if the captive has substantial outside ownership (i.e., stockholders other than the subject parent), ${ }^{24}$ and the Federal Appellate Courts have upheld premium deductibility if at least 30 percent of the captive's business is from exposures unrelated to the parent ${ }^{25}$. Also, the Federal Tax Court has upheld the tax-deductibility of premiums paid by brother/sister subsidiaries of the parent, while denying the deductibility of premiums paid by the parent, as long as the subsidiaries neither own the captive nor consolidate their financial statements with the captive ${ }^{26}$.

\section{Standards for evaluating captive insurance}

\subsection{Judicial standards}

In recent decisions, the federal courts have identified a three-pronged test for determining whether or not premiums paid to a captive, and reserves held by a captive, are taxdeductible ${ }^{27}$. The three prongs of this test are: (1) the presence of an insurable risk, (2) the operation of the business of insurance in its commonly accepted sense, and (3) the existence of risk shifting and risk distribution. These criteria are central to the issue because they provide direct insight into the question of whether or not the business transaction between a parent and its captive is economically efficient.

\subsection{The business of insurance}

\section{Facts and circumstances}

The first two prongs of the judicial test are consistent with the Internal Revenue Code's definition of an insurance company, in which the emphasis is on the insurance contract and the operations of the company. In our view, these two prongs provide the basis for a "facts and circumstances" analysis requiring:

- the existence of some exposure to loss, and a premium payment in return for the insurer's promise to perform in the event of loss, where it is reasonably possible that the insurer will realize a significant loss, and

- several necessary characteristics of an insurance company, including a business purpose, compliance with regulation, risk bearing, risk selection (underwriting/pricing), claims

\footnotetext{
${ }^{23}$ See the O.I.L., Ltd. case.

${ }^{24}$ See the O.I.L., Ltd. case.

25 See the $O D E C O$, Sears, Amerco, and Harper cases.

26 See the Humana and Malone and Hyde cases.

${ }^{27}$ See the Sears, Amerco, and Harper cases.
} 
management, and to some extent also financial management, loss control, administration, and marketing.

Satisfying this analysis is necessary, but not sufficient, to comply with the two "business of insurance" prongs of the courts' test. If a captive's operations are not subject to the economic forces of the insurance marketplace, then there is no assurance that the captive will engage in the business of insurance as it is commonly understood; as in the case of selfinsurance, there is the potential for economic inefficiency.

One crucial means of ensuring market forces, and therefore the business of insurance and economic efficiency, is the presence of substantial business that is unrelated to, or at least independent of, the parent-insured. Unrelated business, as it is generally understood, arises from the exposures of parties that are not members of the same corporate group as the parent. However, we believe that, in a group of companies with a corporate-layered structure, a brother/sister subsidiary of the parent may also be the source of independent business if the subsidiary is not compelled or coerced by the parent to purchase insurance from the captive.

In this context, it is the independence of the unrelated-insured from the potential or actual control of the parent-insured that is at issue. This notion is clearly distinct from the independence of the captive from the control of its parent that is relevant in the context of attempts to pierce the corporate veil in the event of captive insolvency ${ }^{28}$.

\section{The Operational independence index}

Consider the simple case in which a captive insurer is owned by a parent corporation, and possibly by other stockholders as well, but there are no other companies in the parent's corporate group that either own part of the captive or purchase insurance from it. In this case, we propose the following operational independence index for measuring the degree to which the captive is subject to market forces independent of the parent:

Operational Independence Index $=$

(I-Proportion of Captive Owned by Parent) (Parent Premiums) + (Non-Parent Premiums). Total Premiums

This index measures the degree of independence between the parent and the captive as the proportion of total premiums that are unrelated to the parent plus a discounted proportion of premiums that come from the parent, where the latter premiums are discounted by the extent to which the parent owns the captive. In the extreme case of a wholly owned pure captive, the index equals zero; in the case of a traditional insurer, the index equals one.

Now consider the more complicated situation in which there may exist any number of holding companies, brother/sister corporations, or other subsidiaries in the parent's corporate group that can be both owners of the captive and purchasers of insurance. One critical issue that immediately arises in the calculation of the operational independence index is whether or not to include the premiums from various brother/sister subsidiaries of the

28 See M. Moshe Porat and Michael R. Powers, 1993, "Captive Insurer Insolvency: Piercing the Corporate Veil," Journal of Insurance Regulation, 12, 2, 221-244. 
parent in the "non-parent premiums" of the formula. As noted previously, we believe that it is reasonable to consider all premiums from a given insured as unrelated to the parent as long as the insured operated independently of the parent to the extent that it was not compelled or coerced by the parent to purchase insurance from the captive rather than from insurance entities outside of the corporate group. If the parent did impose such restrictions on the subsidiary, then all of the subsidiary's insurance contracts with the captive should be viewed as contracts between the parent and the captive for purposes of computing the operational independence index, and no separate value of the index need be calculated for the subsidiary.

In cases where brother/sister subsidiaries are able to make their insurance purchases independently of the parent's control, it is necessary to broaden the expression for the operational independence index to account for the fact that the net worth of the subsidiary will be vulnerable if the captive becomes financially weak. This vulnerability occurs not just through the subsidiary's extent of ownership (if any), but through the entire corporate group's ownership. Thus, for the subsidiary,

Operational Independence Index =

$\frac{(I-V u l n e r a b i l i t y ~ I n d e x)}{(\text { Subsidiary Premiums })+(\text { Non }- \text { Subsidiary Premiums })}$,

where the vulnerability index is the larger of the following two items:

Proportion of Captive Owned by Subsidiary, or

(Proportion of Captive Owned by Group) $\times$ (Subsidiary's Share of Group's Net Worth) .

In proposing this measure of the subsidiary's vulnerability, we note that, as a matter of pragmatic business, the subsidiary may be called upon to help the captive if it is in financial trouble; also, in the event of an insolvency of the captive, the subsidiary may be subject to the piercing of its corporate veil by third parties to the extent that it is not fully independent of the parent and the captive ${ }^{29}$.

It is important to note that this extension of the operational independence index would effectively adjust for the case in which a parent corporation tried to restructure its corporate group to take advantage of the Humana decision. For example, if the parent of a wholly owned pure captive simply created a holding company with little net worth to serve as the nominal owner of both the parent and the captive, then, under Humana, the parent would become a brother/sister corporation eligible to deduct insurance premiums paid to the captive. However, the generalized operational independence index would recognize this ruse by using

Vulnerability Index =

(Proportion of Captive Owned by Group) $\times$ (Subsidiary's Share of Group's Net Worth) $\approx 1$.

\subsection{Risk shifting and risk distribution}

The third prong of the courts' test-the existence of risk shifting and risk distribution-presents some confusion because these concepts have been used to mean different

${ }^{29}$ See Porat and Powers, 1993. 
things by different authorities, and have been misused by both the courts and taxpayers. In this section, these two concepts will be considered separately, from both the insured's and the insurer's perspectives.

\section{Risk shifting}

Risk shifting involves the transfer of responsibility for the payment of losses from a ceding party (the insured) to an assuming party (the insurer). From the perspectives of both the insured and the insurer, risk is shifted if the assuming party provides a reasonable guarantee to pay for losses. In this regard, it is not crucial that the party assuming risk be involved in the business of insurance; rather, it is possible for risk to be shifted to any financial or other entity that provides a reasonable guarantee to pay the insured's losses when they occur. Thus, risk shifting may occur between any two entities, even related ones.

In the context of captive insurance tax policy, the question is not really whether risk shifting takes place, but rather to what extent a risk transfer is sufficiently economically efficient, from the insured's perspective, to warrant a tax deduction that is consistent with government policy. In evaluating the efficiency of a risk transfer, it is appropriate to consider only the portion of the insurance premium that relates to the variability of losses-that is, the risk premium, from the insured's perspective, or the risk loading, from the insurer's perspective.

If one accepts, as a baseline, that government policy considers a transfer of risk to a traditional insurer to be fully efficient, then it follows that a fully efficient risk transfer occurs when the reduction in the variability of the insured's losses as a result of the risk transfer is greater than or equal to the reduction in the variability of the insured's losses that would result from a similar risk transfer to a traditional insurer. In situations where the reduction in the variability of losses using a captive insurer is less than what it would be using a traditional insurer, it can be argued that the risk transfer is only partially efficient.

\section{Risk distribution}

Risk distribution refers to increases in the stability of an insurance company or other risk pooling arrangements primarily by increasing the number of independent exposure units and the operation of the law of large numbers. In the case of a simple risk pool, where each individual member cedes one exposure unit to the pool and assumes responsibility for paying a proportional share of the pool's total losses, an increase in the number of members reduces the variability of each member's loss payment. In the case of an insurance company, where increased stability is associated with a smaller probability of insolvency, an increase in the number of exposures must be accompanied by an appropriate adjustment in the level of capital, and risk distribution may also be achieved simply by increasing the company's initial capitalization ${ }^{30}$.

By reducing an insurer's probability of insolvency, risk distribution has the effect of enhancing the efficiency of risk transfers because it enhances the insurer's ability to make

${ }^{30}$ See, for example, Michael L. Smith and Stephen A. Kane, 1994, "The Law of Large Numbers and the Strength of Insurance," in Insurance, Risk Management, and Public Policy, S. Gustavson and S. Harrington, eds., Norwell, MA: Kluwer Academic Publishers. 
good on its promises ${ }^{31}$. This is the principal effect of risk distribution from the insured's perspective. From the insurer's point of view, risk distribution represents the fundamental mechanism for maintaining a solvent risk-assuming enterprise.

\section{Unrelated business and the business of affiliates}

The Service's contention that risk is not reduced regardless of the amount of unrelated business in the captive's portfolio is, under reasonable assumptions, statistically correct since the total risk in the captive increases with each additional exposure unit, and therefore the probability of insolvency increases if there is no appropriate adjustment of capital. The argument that the average risk decreases with each additional exposure is also statistically correct and essentially recognizes a manifestation of the law of large numbers. These two observations are not contradictory, but have to be put in the right context.

Adding unrelated risks to the portfolio of related risks tends to increase the total risk of the portfolio, but it is assumed that any responsible company in compliance with regulatory standards will appropriately adjust its capital (or already have sufficient capital) so that the probability of insolvency will not rise above some tolerable threshold. At the same time, increasing the number of exposures tends to decrease the average risk (per exposure), causing a reduction in the variability of the insurer's loss ratio; however, the level of capital must still be appropriately adjusted to ensure that the probability of insolvency remains tolerable.

These statistical effects of risk distribution are the same, whether the additional exposures come from related or unrelated risks, as long as the exposures are statistically independent (as shown in Figures 6 and 7). As noted above, however, unrelated risks have the unique effect of subjecting the captive's operations to the economic forces of the insurance marketplace, thereby ensuring that the captive will behave more like an insurer in the commonly accepted sense. Thus, a company like Allstate (until recently a wholly owned captive of Sears) may be considered a full-fledged insurance company not because the large proportion of unrelated risks reduces the risk of its owner, but rather because their existence makes the captive's operations indistinguishable from those of a traditional insurer.

Similar risk distribution could be achieved if Allstate's exposures were all from Sears (and Sears alone were sufficiently large), but, under such circumstances, this would not subject Allstate to the appropriate market forces. Therefore, one must conclude that risk distribution in a statistical sense may enhance the efficiency of a risk transfer, but by itself does not ensure that a captive will behave like a traditional insurer. For a large self-insurer, all of the elements of risk distribution may exist, but this does not warrant tax-deductibility under current tax policy. It is the unrelated business that adds the dimension of market forces, regardless of the amount of risk distribution that takes place.

\section{The transfer efficiency index}

To measure the efficiency of a given risk transfer from a parent to a captive insurer, we propose the following transfer efficiency index:

${ }^{31}$ See the majority opinion in the case of Gulf Oil Corp. v. Commissioner, 89 T.C. 1010, 1026-27 


$$
\text { Transfer Efficiency Index }=\frac{\text { Reduction in Variance of Losses Using Captive }}{\text { Reduction in Variance of Losses Using Traditional Insurer }} .
$$

This index expresses the efficiency of a risk transfer using a captive as the ratio of the reduction in the variance of the insured's losses as a result of the risk transfer to the captive to the reduction in the variance of the insured's losses that would result from a similar risk transfer to a traditional insurer. In short, the index uses the risk transfer to a traditional insurer (for which the index equals one) as the standard for evaluating the efficiency of all other risk transfers. In most applications, the index will take on values from zero to one; if the index is less than one, then the transfer is said to be only partially efficient.

In the Appendix, we show that, under certain reasonable conditions, this index is bounded above as follows:

Transfer Efficiency Index $\leqslant I$ - (Proportion of Captive Owned by Parent) $)^{2}$.

The upper bound is useful because it allows the Service to compute estimates of the transfer efficiency index that are conservative in the sense that they give taxpayers the benefit of the doubt. (This bound in used to calculate the transfer efficiency index for various examples in Section 7.)

\section{Implementing standards}

\subsection{Overview}

In this section, we propose a comprehensive method for assessing the tax-deductibility of both premiums paid to a captive and reserves held by the captive. This approach is consistent with the three-pronged test promoted by the federal courts in that it requires demonstration of the business of insurance in both the contractual transaction and the operations of an insurance company. However, the proposal includes an improved third prong that relates to risk shifting and risk distribution, not as they have been interpreted by the Service or the courts in the past, but in a manner fully consistent with insurance theory and intuition, and in a manner that is also more reasonable and fair to all parties involved.

The proposed approach consists of two steps. In the first step, a "facts and circumstances" analysis is conducted to determine whether or not the arrangement between the parent and the captive involves the "business of insurance" as it is commonly practiced. In the second step, a tax-deductibility index is computed to measure the degree to which the tax-deductibility of insurance premiums and/or reserves is justified.

We believe that this approach is fair and reasonable because the tax-deductibility index allows for partial deductibility rather than simply "all or nothing" solutions. The proposal is also highly practical in that it responds to all of the derivative captive structures such as group ownership, the writing of unrelated risks, and the writing of risks from brother/sister corporations.

\subsection{Facts and circumstances}

To determine whether a captive insurer satisfies the "business of insurance" test, the captive must be evaluated according to each of the following ten criteria: 
(1) Contracts of insurance risk.

Existence of random hazard, insurance contract, premium, performance in case of loss, and possibility of significant loss.

(2) Business purpose.

Existence of legitimate rationale for forming captive other than potential tax benefits.

(3) Compliance with regulation.

Existence of licenses, financial statements, and rate and policy filings.

Adherence to solvency standards.

(4) Risk bearing.

Existence of risk retention and sufficient capitalization. Absence of counter agreements, retrospective arrangements, financial guarantees, etc.

(5) Risk selection (underwriting/pricing).

Existence of methods for selecting and evaluating risks, calculating arm's-length premiums, allocating premiums to other subsidiaries, and actuarial review.

(6) Claims management.

Existence of procedures for recording and investigating claims, setting reserves, and settling claims.

(7) Financial management.

Existence of relationship with banks, portfolio management, and investment strategy.

(8) Loss control.

Existence of procedures for preventing losses, controlling loss variability, and reducing moral hazard and adverse selection.

(9) Administration.

Existence of staffing, office space, legal counsel, and accounting and auditing functions.

(10) Marketing.

Existence of production management for related and unrelated risks, as well as reinsurance.

As a necessary condition for a captive insurer to conduct the "business of insurance" as it is commonly understood, the captive must satisfy each of items (1) through (6) on this list. In addition, the captive should satisfy items (7) through (10) to some degree, although none of these four items individually is absolutely necessary. Because each of these ten characteristics admits many variant forms, the analysis of a particular captive should be conducted using commonly accepted norms rather than extreme cases. Any substantial deviation from industry norms in any one of items (1) through (6) would be evidence that a captive is not engaged in the business of insurance as commonly understood. Any substantial deviation in items (1) through (10) collectively would also be evidence that a captive is not conducting the business of insurance.

\subsection{The tax-deductibility index}

From the discussion of previous sections, it follows that the extent to which the taxdeductibility of an insurance premium is justified is a function of both: 
(1) the degree to which the captive insurer is constrained by market forces to engage in the business of insurance, and (2) the efficiency of the risk transfer.

To measure the degree to which the tax-deductibility of an insurance premium is justified, we propose a heuristic tax-deductibility index. This index is constructed as a weighted average of the operational independence index, which measures the extent to which the captive is subject to market forces, and the transfer efficiency index, which measures the efficiency of the risk transfer from the parent to the captive. The weights applied to the two indices are the expected loss and expense ratio and the risk loading, respectively. Thus,

Tax Deductibility Index =

(Expected Loss and Expense Ratio) (Operational Independence Index)

+ (Risk Loading) (Transfer Efficiency Index) .

The rationale for the tax-deductibility index is that the portion of the insurance premium covering expected losses and expenses should be deductible only to the extent that the captive insurer is constrained by market forces to operate like a traditional insurer, whereas the portion constituting the risk loading should be tax-deductible only to the extent that the risk transfer is efficient ${ }^{32}$.

In applying the tax-deductibility index, it is assumed that the premium paid by the parent is an arm's-length payment that does not differ significantly from premium levels prevailing in the insurance market during the coverage period. The purpose of the index is thus not to correct premiums in excess of market levels (which would presumably be denied by the Service as unreasonable), but rather to identify the portion of an arm'slength premium that is worthy of a tax deduction.

In evaluating the tax-deductibility of reserves, the tax-deductibility index simplifies to the operational independence index. The use of this latter index alone is sufficient because the efficiency of the risk transfer is not relevant, and the only consideration is the extent to which the captive is constrained by market forces to operate like a traditional insurer ${ }^{33}$. Here it must be assumed that the captive's reserves are established in an arm's-length manner comparable to reserving methods used by other insurers in the market.

\subsection{Estimating parameters}

As noted above, the calculation of the tax-deductibility index requires that the arm'slength premium be broken down into proportions representing the expected loss and expense ratio and the risk loading, respectively. Because these parameters will vary from one line of business to another, the Service would have to establish a consistent standard for each line of business. These standards could be estimated using average ratios for all

32 Given this motivation, the index could also be employed as a formula for the partial tax-deductibility of insurance premiums when its value is less than one. This partial deductibility has the advantage of treating various derivative entities (i.e., captives with multiple owners, with risks unrelated to the parent, or with risks from brother/sister corporations) more equitably than would any "all or nothing" solution.

${ }^{33}$ To determine partial tax-deductibility, the operational independence index could simply be multiplied by the reserves that the captive has established to pay for the parent's losses. 
traditional insurers writing in the United States. Such calculations may be based upon raw data provided by the National Association of Insurance Commissioners.

To calculate the operational independence index and the transfer efficiency index, the Service would require ownership proportions for all parents of a captive, and premium proportions for all insureds of the captive. Much of this information may be obtained from annual financial statements filed by the captive with regulators, although some specific details would have to be provided separately.

\section{Illustrative examples}

To see how the various indices described above would be calculated in the real world, a series of scenarios are considered in Exhibits 1 through 7. Each of these scenarios corresponds conceptually to a prominent legal case mentioned earlier in the article, although the actual numerical values used in the examples have been simplified for ease of exposition.

For each scenario, it is assumed that the expected loss and expense ratio of the arm'slength premium equals 60 percent, and therefore that the risk loading equals 40 percent. It is also assumed that the transfer efficiency index is given by the upper bound discussed above. The specific facts underlying each scenario are presented in the corresponding exhibit.

\subsection{Wholly owned pure captive}

In the first example, presented in Exhibit 1, the captive insurer is wholly owned, and writes only the risks of its parent. This scenario is comparable to the Carnation case, in which the courts upheld the Service's denial of any tax deductions. From Exhibit 1, one can see that the tax-deductibility index is zero, indicating that, consistent with Revenue Ruling 77-316, premiums should not be tax-deductible. Likewise, the operational independence index is also zero, implying that reserves should not be tax-deductible either.

Exhibit 1: Wholly owned pure captive

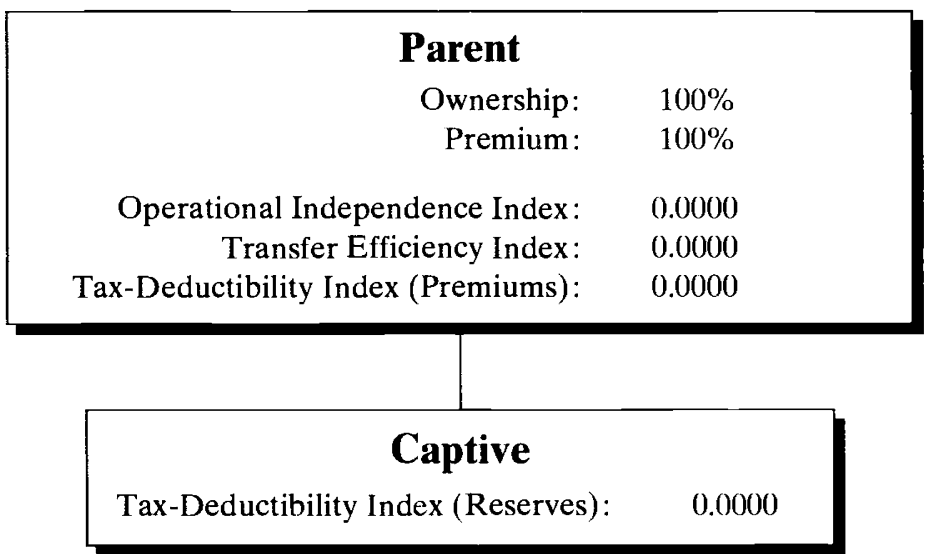




\subsection{Wholly owned broad captives}

The second example, presented in Exhibit 2, again involves a captive insurer that is wholly owned. However, in this scenario almost all of the captive's risks are unrelated to the parent, as in the Sears case, where the courts sided with the taxpayer, permitting the full tax-deductibility of premiums. From Exhibit 2, one can see that the tax-deductibility index is 0.594 , indicating that there is substantial, but not complete, justification for the tax-deductibility of premiums paid to the captive. In this case, the operational independence index is 0.99 , implying that there is virtually complete justification for the tax-deductibility of reserves.

Exhibit 2: Wholly owned broad captive ( $99 \%$ Unrelated Risks)

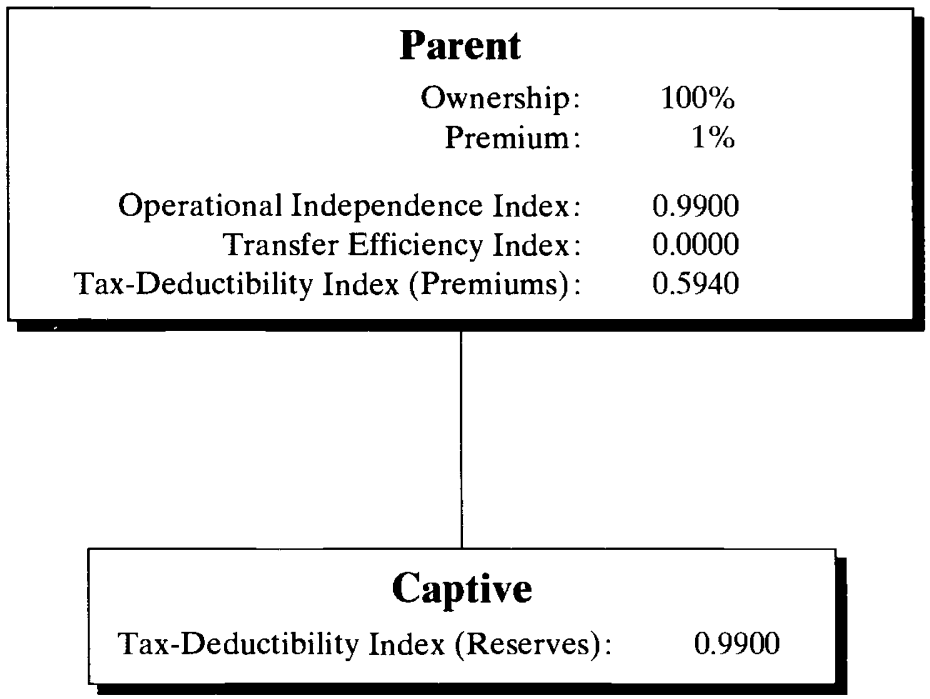

The next example, shown in Exhibit 3, is similar to the second example except that only 30 percent of the captive's risks are unrelated to the parent. This setting corresponds to the Amerco case, in which the courts again sided with the taxpayer, permitting the full tax-deductibility of premiums. From Exhibit 3, it can be seen that the tax-deductibility index is now 0.18 , indicating that there is only modest justification for the tax-deductibility of premiums. Here the operational independence index is 0.30 , implying that there is somewhat more justification for the tax-deductibility of reserves. 
Exhibit 3: Wholly owned broad captive

(30\% Unrelated Risks)

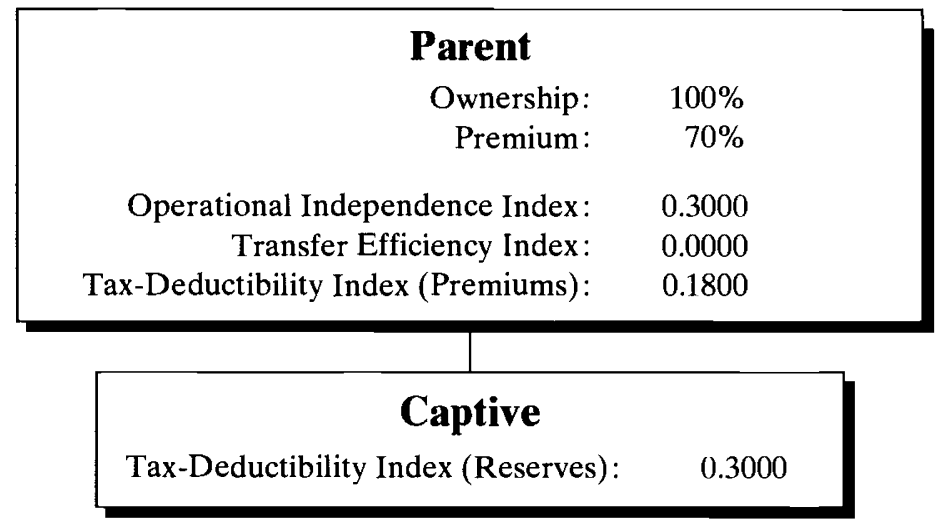

\subsection{Group-owned captive}

In the fourth example (Exhibit 4), the captive insurer is group-owned, with 25 parent owners, each of which owns 4 percent of the captive, and accounts for 4 percent of the captive's risks. This case is comparable to O.I.L., Limited, which was permitted a full tax deduction for premiums consistent with Revenue Ruling 78-338. Exhibit 4 reveals that, in this arrangement, which resembles risk pooling, the tax-deductibility index is very close to one $(0.9984)$ for each parent, and so the tax-deductibility of premiums is virtually completely justified. Similarly, the (premium weighted) average operational independence index for all insureds is also 0.9984 , so that the tax-deductibility of reserves is also virtually completely justified.

Exhibit 4: Group-owned captive

(25 Unaffiliated Parents Each Owning 4\%)
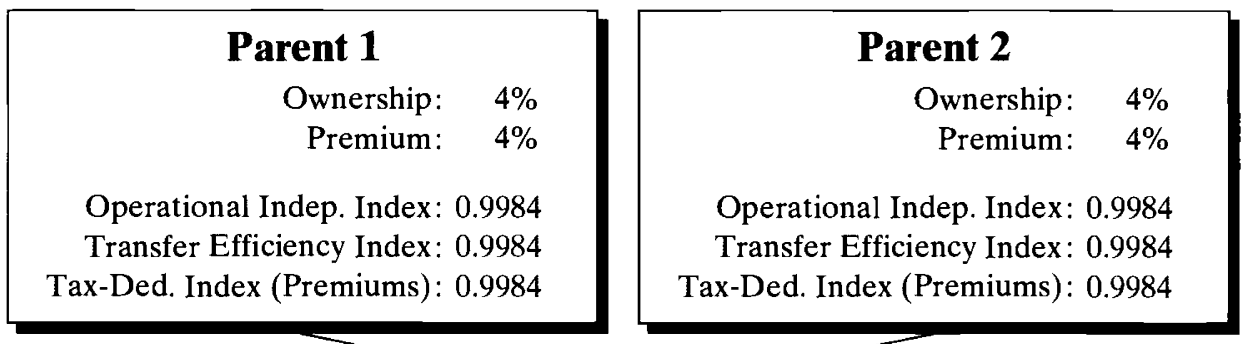

\section{Captive}

Tax-Deductibility Index (Reserves): $\quad 0.9984$ 


\subsection{Wholly owned captive with independent brother/sister insured}

The fifth example (Exhibit 5) returns to the case of a wholly owned captive. However, in this scenario, which corresponds to the Humana case, some of the captive's risks are unrelated to the parent, but originate from a brother/sister subsidiary of the parent. Assuming that the subsidiary is not forced or coerced by the parent to purchase insurance from the captive, it is necessary to use the broadened expression for the operational independence index to account for the fact that the net worth of the brother/sister subsidiary will be vulnerable if the captive becomes financially weak.

\section{Exhibit 5:}

Wholly owned captive with independent brother/sister insured

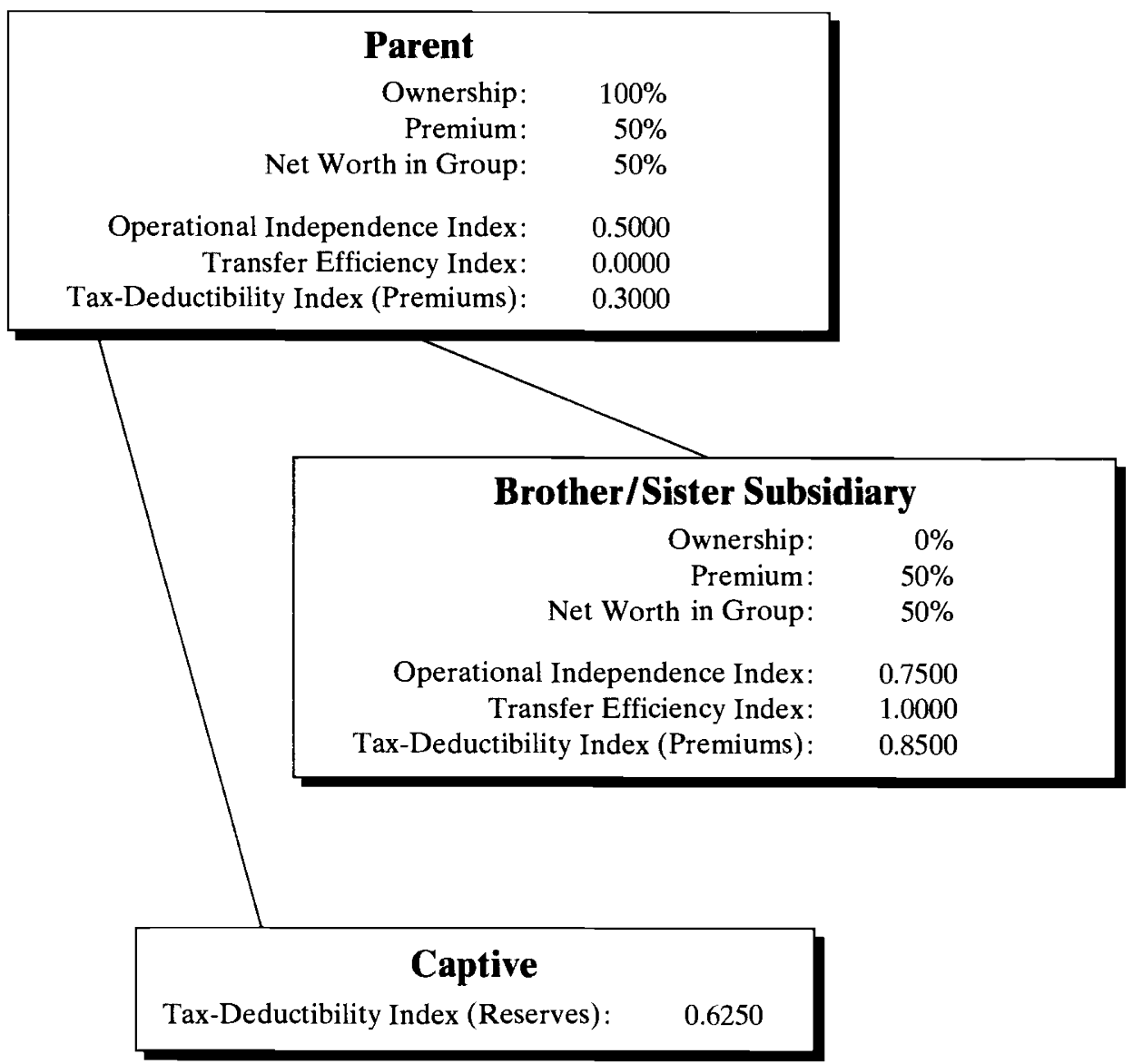


In Humana, the courts denied the tax-deductibility of premiums for the parent corporation, but permitted the full tax-deductibility of premiums for brother/sister subsidiaries. From Exhibit 5, one can see that the tax-deductibility index for the parent is 0.30 , and for the subsidiary is 0.85 ; thus, there is substantially greater justification for the tax-deductibility of premiums paid by the subsidiary than for premiums paid by the parent. In this case, the (premium weighted) average operational independence index for the two insureds is 0.625 , indicating that there is substantial, but not complete, justification for the tax-deductibility of reserves.

\subsection{Wholly owned captive with dependent brother/sister insured}

In the sixth example (Exhibit 6), we consider what would happen if the fifth example were modified to be like Hypothetical Company $A$ of Figure 4 ; i.e., the captive insurer remains wholly owned, but the brother/sister subsidiary is forced by the parent to purchase insurance from the captive. Under these assumptions, the business of the subsidiary should be combined with that of the parent for computing the operational independence index (which is zero for both entities). The tax-deductibility index for the parent is then zero, and for the subsidiary is 0.40 . In this case, the (premium weighted) average operational independence index for the two insureds is clearly zero, indicating that reserves should not be tax-deductible.

\section{Exhibit 6:}

Wholly owned captive with dependent brother/sister insured

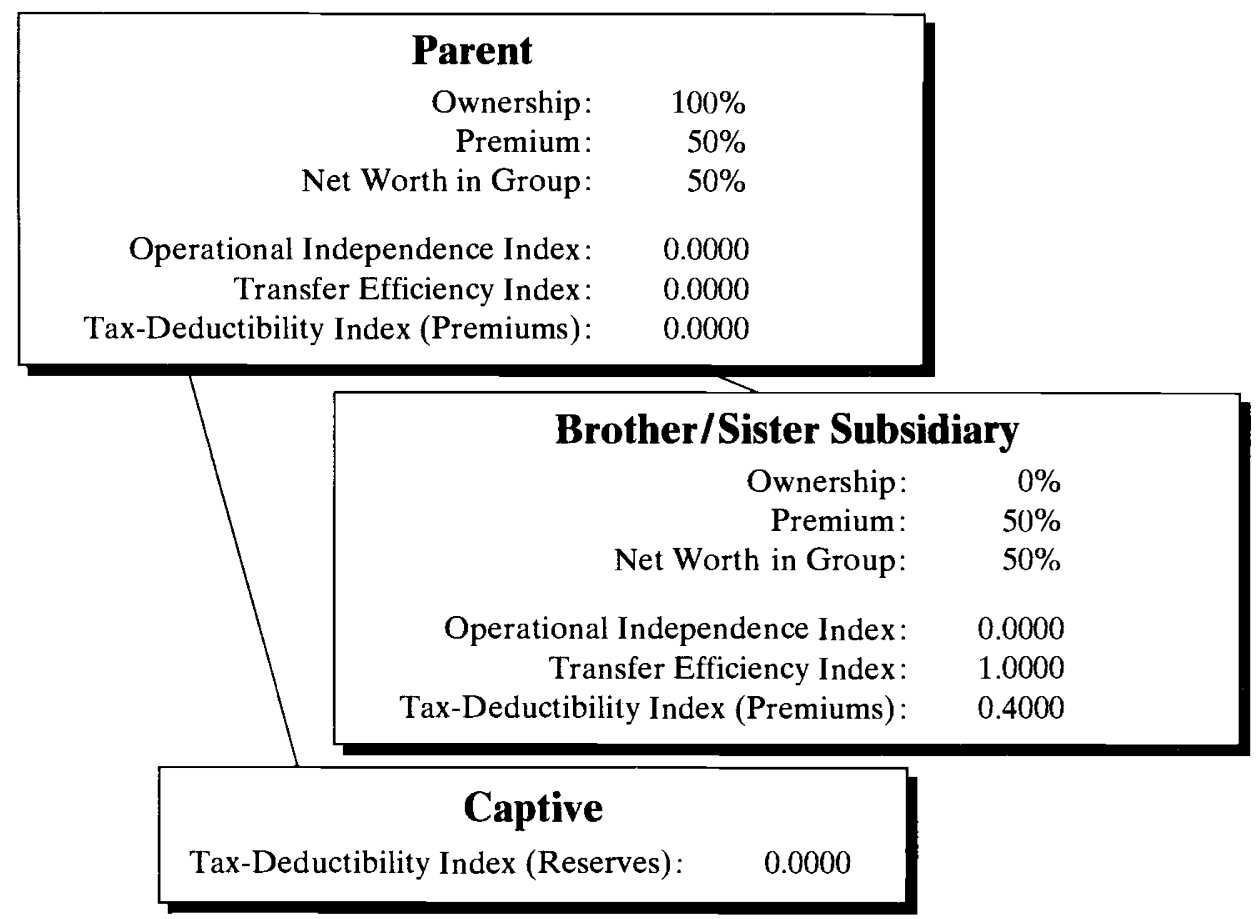




\subsection{Wholly owned captive with holding company parent}

The seventh and final example (Exhibit 7), is similar to the fifth example in that the captive is wholly owned, and some of the captive's risks originate from a brother/sister subsidiary that is not forced or coerced to purchase insurance from the captive. However, in this scenario the parent is a holding company with little net worth, which may have been organized simply to take advantage of the tax deductions permitted by Humana. From Exhibit 7, one can see that the tax-deductibility index for the parent is 0.594 , and for the subsidiary is 0.4119 ; in this case, the parent has a greater index because it accounts for so little of the captive's business, increasing its operational independence. Overall, the (premium weighted) average operational independence index for both insureds is 0.0296 , indicating that there is virtually no justification for the tax-deductibility of reserves.

\section{Exhibit 7:}

Wholly owned captive with holding company parent

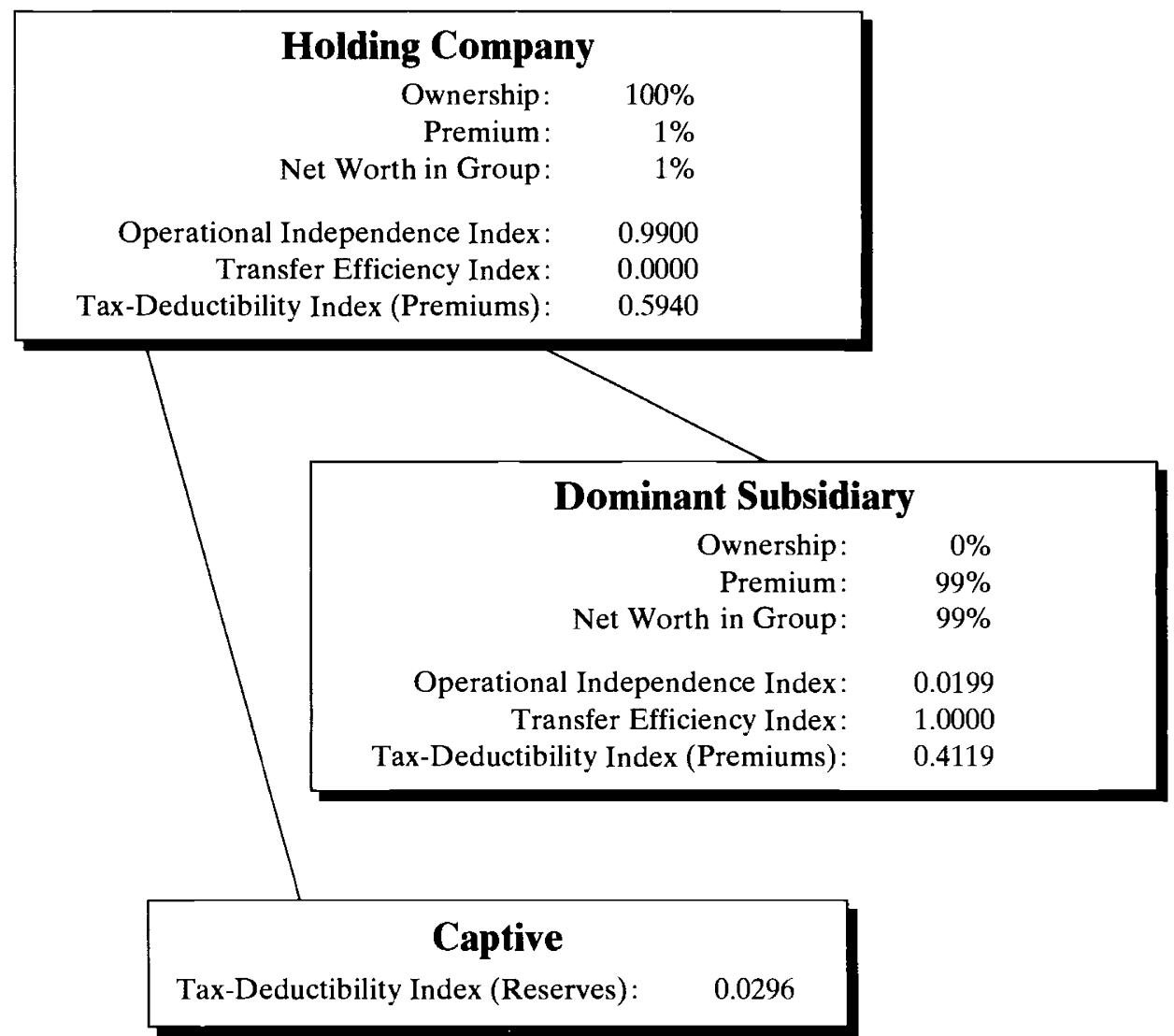




\section{Summary}

The global controversy surrounding captive insurance tax policy has persisted for many years, and is likely to continue into the future. In this article, we clarified various aspects of the controversy, and proposed a comprehensive solution to the problem. The proposed solution involves the use of a tax-deductibility index measuring the degree to which the deductibility of premiums paid to a captive is justified; the deductibility of reserves is addressed by a special case of the index.

Fig. 9: Captive insurer tax-deductibility decision process

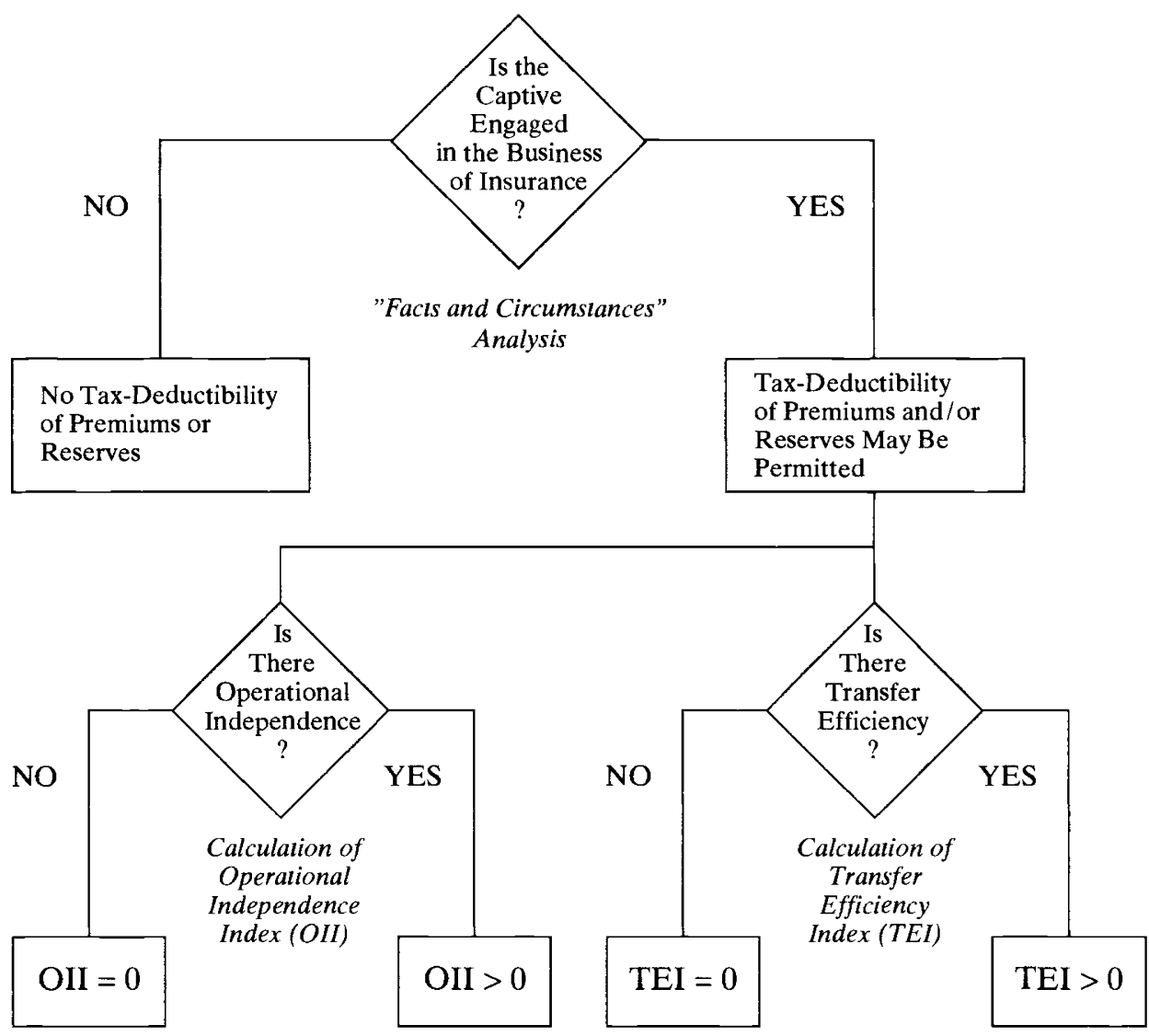

Tax - Deductibility Index for Premiums $=($ Expected Loss and Expense Ratio $) \times(O I I)$ $+($ Risk Loading $) \times(T E I)$

Tax - Deductibility Index for Reserves $=O I I$ 
As shown in the flowchart of Figure 9, the actual implementation of the tax-deductibility index follows a two-step process:

Step 1: To evaluate whether or not the arrangement between the parent and the captive constitutes the "business of insurance" as it is commonly practiced, one must perform a "facts and circumstances" analysis.

- The insurance contract must reflect a situation in which the parent faces some exposure to loss and the captive accepts an arm's-length premium in return for agreeing to perform in the event of loss, where it is reasonably possible that the captive may realize a significant loss (affirming that the contract actually transfers risk).

- The insurer must satisfy several necessary characteristics of an insurance company, including (1) contracts of insurance risk, (2) a real business purpose, (3) compliance with regulatory requirements, (4) risk bearing, (5) risk selection (underwriting/pricing), and (6) claims management. Also, to some degree, the insurer must carry out the functions of (7) financial management, (8) loss control, (9) administration, and (10) marketing.

If the captive satisfies the requirements of this analysis, then it may be eligible for taxdeductibility, as determined in the next step.

Step 2: Computation of the tax-deductibility index. This step involves several calculations.

- The operational independence index and the transfer efficiency index must be computed.

- The arm's-length insurance premium must be partitioned into two proportions, one for the expected loss and expense ratio, and the other for the risk loading.

- The tax-deductibility index must be computed as a weighted average of the other two indices; for reserves, the operational independence index is used by itself.

We believe that the proposed approach is both theoretically sound and intuitively appealing. It is fair and reasonable to all parties involved, allowing for partial tax-deductibility rather than simply "all or nothing" solutions. The proposal is also highly practical in that it responds to all of the derivative captive structures such as group ownership, the writing of unrelated risks, and the writing of risks from brother/sister corporations.

\section{Appendix}

Let $T_{S}$ denote an ordinary risk transfer between a ceding party ("buyer"), $B$, and an assuming party ("seller"), $S$, in which: (1) $B$ faces a random loss amount, $X \sim F(x), x \in \mathbf{X}$ $\underline{\mathrm{C}}[0,+\infty)$, and is willing to pay an insurance premium to transfer responsibility for all or part of $X$, and (2) $S$ agrees to pay an amount $T(x)$ to $B$ whenever $X=x$, in return for a premium payment from $B$ to $S$. (To reduce problems of moral hazard, it is assumed that $T(x)$ is a non-decreasing function of $x$ such that $T(x) \in[0, x]$.)

From the text, it follows that the transfer efficiency index of the risk transfer $T_{S}$ from the insured $B$ to the insurer $S$ is given by 


$$
\left.\varphi_{B}\left(T_{S}\right)=\frac{\operatorname{Var}[X]-\operatorname{Var}\left[X-\left(1-\gamma_{B}\right) T\right]}{\operatorname{Var}[X]-\operatorname{Var}[X-T]}\right\}
$$

where $\gamma_{B} \in[0,1]$ denotes the proportion of $S$ that is owned by $B$ on a consolidated basis. This index may be rewritten as follows:

$$
\begin{aligned}
\varphi_{B}\left(T_{S}\right) & =\left(1-\gamma_{B}\right)\left\{\frac{-\left(1-\gamma_{B}\right) \operatorname{Var}[T]+2 \operatorname{Cov}[X, T]}{-\operatorname{Var}[T]+2 \operatorname{Cov}[X, T]}\right. \\
& =\left(1-\gamma_{B}\right)\left(1+\frac{\gamma_{B}}{2 \beta-1}\right),
\end{aligned}
$$

where $\beta=\frac{\operatorname{Cov}[X, T]}{\operatorname{Var}[T]}$.

The following theorem identifies a class of risk transfers $T_{S}$ for which $\varphi_{B}\left(T_{S}\right)$ is bounded.

Theorem: If $T_{S}$ is such that $\beta \geqslant 1$, then

$\varphi_{B}\left(T_{S}\right) \in\left(1-\gamma_{B}, 1-\gamma_{B}^{2}\right]$.

Proof: First, note that $\varphi_{B}\left(T_{S}\right)=1$ for $\gamma_{B}=0$ and $\varphi_{B}\left(T_{S}\right)=0$ for $\gamma_{B}=1$, so that the theorem holds trivially for these cases. For $\gamma_{B} \in(0,1)$, Equation (1) implies that

$$
\frac{\partial \varphi_{B}\left(T_{S}\right)}{\partial \beta}=-\frac{2 \gamma_{B}\left(1-\gamma_{B}\right)}{(2 \beta-1)^{2}}<0
$$

for $\beta \geqslant 1$, and so $\varphi_{B}\left(T_{S}\right)$ is a decreasing function of $\beta$. Then, since $\varphi_{B}\left(T_{S}\right)=1-\gamma_{B}{ }^{2}$ for $\beta=$ 1 and $\lim _{\beta \rightarrow \infty} \varphi_{B}\left(T_{S}\right)=1-\gamma_{B}$, it follows that

$$
1-\gamma_{B}<\varphi_{B}\left(T_{S}\right) \leqslant 1-\gamma_{B}{ }^{2}
$$

for $\beta \geqslant 1$.

Note that $\beta=\frac{\operatorname{Cov}[X, T]}{\operatorname{Var}[T]}$ represents the slope of the line of best fit for the least squares regression of $X$ against $T$. Since $T(X)$ is a non-decreasing function of $X$ through the origin such that $T(X) \leqslant X$, it follows that the inverse function $X(T)$ will be a non-decreasing function of $T$ through the origin such that $X(T) \geqslant T$. Thus, a good linear approximation of the inverse function will tend to have a slope greater than or equal to one, and so the bounds provided by the theorem will tend to hold in practice. For the special case in which $T$ denotes the proportional insurance contract

$$
T(x)=\alpha x,
$$

for some $\alpha \in(0,1]$, it can easily be shown that $\beta=\frac{1}{\alpha}$. It then follows from Equation (1) that

$$
\varphi_{B}\left(T_{S}\right)=\left(1-\gamma_{B}\right)\left(1+\frac{\alpha \gamma_{B}}{2-\alpha}\right),
$$

which increases from $1-\gamma_{B}$ at $\alpha=0$ to $1-\gamma_{B}{ }^{2}$ at $\alpha=1$. 


\section{REFERENCES}

HEAD, George L. and PORAT, M. Moshe, 1990, "Tax Treatment of Pre-Loss Risk Financing CostA Public Policy Perspective", Journal of Insurance Regulation, 8, 4, 394-407.

PORAT, M. Moshe, 1988, "Captive Insurance Companies: Concepts, Developments, and Risk Management Applications", in Issues in Insurance, Malvern, PA: American Insurance Institute.

PORAT, M. Moshe, et al., 1991, "Market Insurance versus Self-Insurance: The Tax-Differential Treatment and Its Social Cost", The Journal of Risk and Insurance, 58, 4, 657-669.

PORAT, M. Moshe and POWERS, Michael R., 1993, "Captive Insurer Insolvency: Piercing the Corporate Veil," Journal of Insurance Regulation, 12, 2, 221-244.

SMITH, Michael L. and KANE, Stephen A., 1994, "The Law of Large Numbers and the Strength of Insurance", in Insurance, Risk Management, and Public Policy, S. Gustavson and S. Harrington, eds., Norwell, MA: Kluwer Academic Publishers. 